\title{
$\underline{\text { A sociedade e a reprodução: um problema político }}$
}

\author{
Fabíola Rohden
}

\section{SciELO Books / SciELO Livros / SciELO Libros}

ROHDEN, F. A sociedade e a reprodução: um problema político. In.: $A$ arte de enganar a natureza: contracepção, aborto e infanticídio no início do século XX [online]. Rio de Janeiro: Editora FIOCRUZ, 2003, pp. 25-45. História e saúde collection. ISBN: 978-65-5708-117-4. https://doi.org/10.7476/9786557081174.0003.

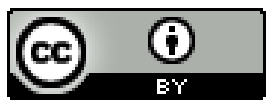

All the contents of this work, except where otherwise noted, is licensed under a Creative Commons Attribution 4.0 International license.

Todo o conteúdo deste trabalho, exceto quando houver ressalva, é publicado sob a licença Creative Commons Atribição 4.0.

Todo el contenido de esta obra, excepto donde se indique lo contrario, está bajo licencia de la licencia Creative Commons Reconocimento 4.0. 


\section{A sociedade e a Reprodução:} um problema político

A mulher incompreensível à primeira vista explica-se por sua missão especial, uma e única, embora complexa. (...) É que a mulher foi criada para ser mãe (...).

Se a esterilidade nos apresenta uma imagem seca e árida do nada, se o triste celibatário só oferece a nossos olhos um coração frio e vazio, devotado ao amor de si próprio, e se ao contrário o nascer de um filho produz as mais deliciosas emoções, como compreende-se que a esterilidade seja algumas vezes considerada um benefício e a fecundidade, esse feliz símbolo de uma natureza sempre nova, uma desgraça que se procura prevenir com precauções misteriosas, destruir às vezes por crimes revoltantes? (Guimarães, 1872:4-6)

As passagens acima pertencem ao estudo realizado por Guilherme Augusto M. Guimarães denominado Da esterilidade. Trata-se de uma tese apresentada à Faculdade de Medicina do Rio de Janeiro no ano de 1872. Este trabalho é um exemplo, entre muitos outros, do enfoque a partir do qual era tratada a questão da reprodução e, sobretudo, do controle da natalidade no Brasil. A fecundidade é vista como uma grande bênção da natureza, e a esterilidade como o maior dos infortúnios. Pior ainda parece ser a impressão causada pela esterilidade provocada por determinadas "precauções misteriosas" ou "crimes revoltantes", como diz o autor. Não se pode deixar de notar também a sua referência à noção de que a mulher fora criada para ser mãe, para perpetuar a geração. Essas idéias permaneceriam por muito tempo orientando pensamentos e atitudes daqueles que seriam 
responsáveis por ditar as normas do que era considerado adequado em termos de reprodução e controle da natalidade.

Embora este livro vá tratar das primeiras décadas do século $\mathrm{XX}$, é necessário enfatizar que muitos dos questionamentos e proposições envolvendo o tema da reprodução já estavam presentes de forma contundente nos debates intelectuais pelo menos desde a segunda metade do século XIX. Nessa época, a questão da fecundação e da fertilidade prendia cada vez mais a atenção dos médicos. O trabalho de Guimarães (1872) é a primeira tese sobre o tema apresentada na Faculdade de Medicina do Rio de Janeiro e vários outros estudos seguiram-se a ela. ${ }^{1}$

O interesse pela esterilidade refletia uma preocupação maior com problemas bem mais amplos e significativos que envolviam o tema da população. Os homens públicos da época, e em especial médicos e juristas que vinham adquirindo cada vez mais prestígio e se convertiam em importantes formadores de opinião, estavam entre os principais participantes dos debates que envolviam este assunto. Em particular, a questão do controle da natalidade ganharia cada vez mais destaque, principalmente a partir do começo do século XX.

Esse é o tema central da tese Preceitos em torno do casamento, elaborada por Crescencio Antunes da Silveira em 1908. O autor inicia o trabalho afirmando que os processos que atuam em detrimento da concepção são imorais. Ofendem a própria definição do casamento. E além de delitos contra a moral e os bons costumes, constituem também um delito contra a sociedade, em especial a brasileira, que tanto precisa de gente para o povoamento do seu solo. A questão do povoamento parece ser a preocupação central deste autor. Além de defender o casamento nos moldes definidos pela medicina e condenar a contracepção, Silveira também propõe a criação de instituições que recolham as crianças filhas de pais necessitados:

E, ao lado dos casais necessitados, por amor à caridade, por espírito de fraternização e em prol da regeneração e do progresso, deverão estar os Poderes, tomando os rebentos da família e a vida da sociedade futura - os filhos - nos braços paternais, levando-os para as instituições em favor da infância; instituições que deverão ser protegidas e espalhadas pelos governos em nosso meio, onde grande parte das crianças, nossas irmãzinhas, choradas e cantadas pela Pátria, estiola-se no seio da miséria ou dando seu último alento ou, se transpõe o vendaval das desventuras, crescendo sem vida e como péssimo fruto às novas gerações [sic]. (Silveira, 1908:9-10) 
O autor acrescenta que o homem patriota tem o dever de aproveitar a semente e o terreno, multiplicando-se e criando as novas gerações. Isto se faz por intermédio do casamento. Silveira opõe a libertinagem, o vício e o celibato ao casamento, à família e à sociedade. Defende que com as uniões saudáveis se poderá construir uma nação habitada por indivíduos de qualidade e em quantidade suficiente. Segundo o autor:

É pelo casamento que podemos organizar uma sociedade sã e forte de que, para o seu progredir, tanto precisa o nosso país, onde havendo, relativamente à área habitável, tão poucos habitantes, duas terças partes aproximadamente são prejudicadas pela trindade horrível - a sífilis, a tuberculose e o álcool - e os outros males hauridos nas fontes da vagabundagem, do vandalismo e da sodomia, agindo em favor da debilidade e da degeneração das raças e da despovoação. (Silveira, 1908:11. Grifos do autor)

No casamento imaginado por Silveira (1908:12), homens e mulheres se subordinariam reciprocamente e ajudariam a constituir o equilibrio das raças e o progresso da civilização:

Os direitos dos conúbios devem ser iguais por natureza, e a civilização, cada dia, aperfeiçoa e garante esta idéia, mostrando que se o homem é o rei dos animais, a mulher é a rainha; e na qualidade destes direitos institui-se uma subordinação recíproca na vida conjugal, estabelecendo o equilibrio da grandiosa união pelo casamento. O casamento é a base da sociedade legitimando a família e ocupa importante lugar, no mundo social, estabelecendo o equilíbrio moral e social das raças.

Nascer e viver dentro da lei é uma das gradações métricas da civilização de um povo.

O autor ainda esmiuça o tema do celibato como contrário às leis da natureza, ao mostrar como a prática do ato sexual é importante. A inação dos órgãos sexuais pode trazer uma série de doenças, como a ninfomania, a histeria, a catalepsia, a melancolia, além de insônia, sonhos eróticos e o "funesto hábito dos prazeres solitários". Só o casamento saudável e ordenado pode pôr fim a todos estes riscos e garantir que a espécie se reproduza de maneira adequada. Parece que, nesse momento, a regulação da sexualidade e do casamento estava definitivamente atrelada a fins bem mais nobres que a satisfação individual. Estavam em jogo o povoamento da pátria e a sobrevivência da espécie. 
Eram estas mesmas questões que faziam com que também a preocupação com a esterilidade fosse ganhando um destaque maior. ${ }^{2}$ A demografia, que vinha arrebatando cada vez mais adeptos e passava a apresentar estudos mais significativos, teve um importante papel nesta mudança. A tese de Pedro Monteiro Gondim defendida em 1911 é um bom exemplo. Um dos méritos do trabalho é mostrar dados referentes à taxa de infecundidade dos casais. O autor cita os trabalhos de Pinard, que comparam dados de Paris, Berlim e Rio de Janeiro. Embora sem explicar como esses números são calculados, afirma que Berlim apresentava uma taxa de infecundidade de $12,8 \%$, enquanto em Paris e no Rio de Janeiro o índice ficava em $11,3 \%$. Outra informação fornecida diz respeito à origem do problema. Segundo ele, em $60 \%$ dos casos a culpa pela infecundidade era da mulher, e em $40 \%$, do homem. Percebe-se que, em contraste com trabalhos anteriores (Guimarães, 1872), que praticamente só se referem à mulher, o homem agora também poderia ser responsabilizado pela não reprodução do casal. $^{3}$

Na tese de Mario Ferreira de Carvalho, de 1922, a diminuição da natalidade é apresentada como a questão central. A tese trata da esterilidade feminina e o autor considera sua relação com a menstruação, a ovulação e todas as possíveis causas anatômicas e fisiológicas. Mas a peculiaridade do trabalho reside em reforçar a idéia de que a esterilidade é um problema grave que tem conseqüências sérias para a ordem social e para a nação, traduzindo uma nova onda mais geral de preocupações. Para o autor, o tema é de atualidade:

diante da diminuição da natalidade proporcional, que muito tem preocupado a atenção de grande número de fervorosos cientistas do nosso meio, no interesse de um futuro brilhante de nossa pátria.

(...) a ausência ou escassez de crianças na família corre, uma ou outra, por conta de ato voluntário dos pais, ou de um deles, os quais, com conseqüência de uma civilização requintada, ou na luta de uma subsistência cada vez mais difícil, procuram contrariar o sentimento natural, que tem todo o ser vivo pela propagação da espécie.

Enquanto há mulheres que se recusam o dever da maternidade, outras existem que vivem no mais ardente desejo de um raio de luz na obscuridade de seus sonhos, na angústia infinita de ser mãe. (Carvalho, 1922:4) 
Da citação anterior pode-se destacar a noção de que a diminuição da natalidade coloca em risco o futuro da pátria. Tem acontecido em função de uma decisão voluntária dos pais, ou seja, em conseqüência do uso de algum método de restrição do número de filhos. E esses pais são tanto os menos favorecidos - que assim procedem pelas dificuldades de subsistência - quanto aqueles que pertencem a uma classe mais alta que, por motivos fúteis, se recusam a ter filhos. Além de prejudicar o país, os dois grupos adotam um comportamento que é 'antinatural'. Segundo o autor, médicos, estudiosos da economia política e da demografia devem se dedicar com afinco à avaliação desse quadro. Nesse contexto, a maternidade e a infância tornam-se assuntos da maior importância.

É interessante que o controle da natalidade e, sobretudo, o aborto e a contracepção passam a ser discutidos não apenas em função das conseqüências que representavam para os indivíduos que os praticavam mas também em relação ao que implicavam em termos de uma ameaça ao crescimento da nação. Esse panorama se tornaria bastante complexo, uma vez que a grande questão da população passava a ser pensada também a partir da eugenia.

Este quadro não era exclusivo do Brasil. Também em outros contextos a natalidade e a 'higiene da raça', expressão que se tornaria muito comum, eram o centro das atenções. ${ }^{4}$ Tanto na Europa quanto nos Estados Unidos, esses temas estavam na ordem do dia dos debates não apenas entre os médicos, mas entre homens públicos, intelectuais e ativistas. $O$ enfoque na quantidade e 'qualidade' da população com vistas ao futuro da nação passaria a caracterizar especialmente a relação entre medicina e poderes públicos.

Um dos fatores centrais a impulsionar os debates era uma percepção generalizada de que as taxas de fecundidade diminuíam consideravelmente em muitos países. O que veio a se chamar de 'transição demográfica' entre 1870 e 1920 era visto como um grande motivo de preocupações. ${ }^{5}$

A redução do número de filhos é descrita por muitos autores como um fenômeno bastante complexo e resultado de uma série de transformações ocorridas nesse período. O que parece ser indiscutível é que, com o acesso a vários métodos, há por parte dos indivíduos uma tentativa mais eficaz de controle da natalidade em marcha na passagem do século XIX para o seguinte. Em vários países verificou-se um aumento no uso de contraceptivos e também na prática do aborto. 
Angus McLaren (1990, 1994), traçando uma história do uso de diferentes métodos de controle da natalidade, salienta que, nas últimas décadas do século XIX, contraceptivos (incluindo camisinhas, pessários, diafragmas e seringas) e abortivos eram anunciados em jornais e revistas, vendidos em lojas e farmácias e mesmo de porta em porta. Além disso, métodos tradicionais, como o coito interrompido, continuaram recorrentes. A abstenção era um recurso importante, especialmente a partir do impacto das campanhas feministas que advogavam um maior autocontrole masculino, no contexto do combate ao duplo padrão moral que também condenava a masturbação e a prostituição. Edward Shorter (1982) afirma que, entre 1880 e 1930 , as mulheres passaram a ter muito mais acesso ao aborto, o que teve como conseqüência uma possibilidade de maior liberação das gravidezes indesejadas. ${ }^{6}$

A partir das polêmicas em torno do aborto nos Estados Unidos na segunda metade do século XIX, é possível perceber uma estreita relação entre a transformação do aborto em um problema político importantẹ, considerando em particular as leis que o colocam na ilegalidade a partir de 1860, com a presença mais significativa dos movimentos feministas (Smith-Rosenberg, 1985).7 As práticas de aborto mudaram naquele país durante o século XIX devido à disponibilização de novos métodos e à transformação da prática do aborto em um serviço comercializado. Novos remédios e instrumentos, como sondas e dilatadores uterinos, passavam a ser vendidos. Em geral, todos os medicamentos que vinham sob o rótulo "medicamentos para mulheres", propondo "regular as funções femininas", escondiam um abortivo em potencial. ${ }^{8}$ Da mesma forma, o título de "médico de mulheres" também trazia consigo a referência a práticas abortivas, o que vai ser combatido pelas campanhas das entidades médicas que tentam regulamentar a profissão (Brodie, 1994).

A aproximação entre contracepção e aborto parecia ser bastante comum naquela época. Contracepção e aborto eram duas estratégias que se confundiam, apesar de algumas tentativas de distinção por parte médicos e dos chamados neomalthusianos. ${ }^{9}$ Para o público em geral, era difícil diferenciar o uso de chás, purgativos e supositórios - usados para 'regular' as mulheres, 'fazendo descer a menstruação' - dos abortivos. ${ }^{10} \mathrm{O}$ aborto faria parte de um contínuo de práticas de controle da natalidade e constituía um recurso usado principalmente pelas mulheres de classes menos favorecidas, que teriam menos acesso aos contraceptivos (McLaren, 1990). 
Em termos gerais, há uma tônica predominante na bibliografia que descreve o século XIX como um momento em que a contracepção torna-se mais acessível e possibilita a diminuição do número de filhos, o que estava a cargo sobretudo do controle individual das mulheres. Para Peter Gay (1984), a contracepção foi um aspecto fundamental na constituição da sexualidade burguesa. O autor ressalva que, apesar de não ser exclusiva da burguesia já que prostitutas, aristocratas e camponeses também faziam uso de métodos contraceptivos -, o que faz o birth control burguês do século XIX único é que largos segmentos de uma classe influente transformaram a contracepção em uma política sistemática de planejamento familiar racional.

Os autores concordam que houve um decréscimo na natalidade, o que gerou inquietações nas autoridades e intelectuais preocupados com a relação entre população e soberania nacional ou aprimoramento da raça. O que se discute são as razões de tal fenômeno. Angus McLaren (1990), por exemplo, se refere às campanhas neomalthusianas não apenas como uma tentativa de limitar o tamanho das famílias, mas como um movimento político mais geral de combate à pobreza e também à promiscuidade. Além disso, destaca que na virada do século era comum responsabilizar as mulheres, que tentavam se libertar das tarefas tradicionais, pelo declínio no tamanho das famílias, embora se possa avaliar o impacto de outros fatores, como o custo cada vez maior com a criação de mais um filho. ${ }^{11}$ Hervé Le Bras (1981), falando da França, detalha as discussões da época a respeito das causas da baixa fecundidade, mostrando que havia uma tensão em se admitir a voluntariedade ou não da redução do número de filhos. Os argumentos giravam em torno da esterilidade ser provocada pela mestiçagem, da 'propagação' de práticas sexuais como o onanismo e a homossexualidade, de doenças como a sífilis ou do feminismo. O tema de uma nova percepção da criança, tese defendida por Philippe Ariès (1973), também é constantemente evocado. ${ }^{12}$

Janet F. Brodie (1994), considerando a situação nos Estados Unidos, afirma que é preciso problematizar a tese de que há uma relação direta entre os avanços tecnológicos e científicos no campo da contracepção que de fato ocorreram e que foram 'democratizados' no final do século XIX - e o declínio na taxa de nascimentos. Para a autora, é mais adequado considerar a difusão de novas atitudes e valores relacionados com uma vontade do casal de querer diminuir o número de filhos ou espaçar os nascimentos. Este desejo de controle reprodutivo faria parte de um impulso 
maior em direção ao controle de suas próprias vidas. Para as mulheres trabalhadoras, a restrição do número de gestações e filhos se tornava especialmente importante. Acrescenta-se a isso o fato de que a propagação dos métodos contraceptivos e o recurso ao aborto se converteram, com o passar do tempo, em um mercado relativamente grande e lucrativo, particularmente no meio urbano.

Em contraste com os argumentos que privilegiam a relação entre natalismo e nacionalismo, principalmente nos casos europeus, a autora destaca como foco das campanhas contra o aborto e a contracepção a preocupação com a liberdade sexual feminina que surgiu em virtude do controle da reprodução. E relata também como estas campanhas foram encabeçadas por ginecologistas que, interessados em trazer prestígio para a nova especialidade médica que então se constituía, tentavam se distinguir de outros profissionais que se prestavam a fazer aborto e contracepção, duas práticas freqüentemente confundidas. Os ginecologistas cada vez mais tentavam definir a saúde da mulher como um problema médico, ao mesmo tempo em que se esforçavam em provar que o médico de mulheres era honesto e de moral ilibada (Brodie, 1994). ${ }^{13}$

O caso francês tem sido intensivamente tratado pela bibliografia sobre o tema, considerando o vulto que a queda da natalidade tomou naquele país. As práticas de controle da natalidade, que começaram a se propagar nas elites desde o fim do século XVIII, tornaram-se recorrentes na segunda metade do século XIX. As grandes famílias vão perdendo terreno. Gradativamente, novas preocupações com o casal e com a criança se desenvolvem. No meio rural francês pratica-se o infanticídio, apesar de todas as condenações, principalmente da Igreja. No meio urbano, a recusa, por parte das mulheres, de ter muitas crianças estaria na origem da propagação do aborto e na utilização de outros métodos, como preservativos, esponjas, pessários e lavagens também entre as classes populares (Thébaud, 1986; Ronsin, 1980; Challier, 1986).

Contudo, a construção sistemática da queda da natalidade como uma questão política e de higiene teria começado após a derrota da França na guerra de 1870. Robert Nye $(1984,1993)$ defende que havia uma ansiedade geral que afetava as nações européias na virada do século, motivada por problemas que estavam relacionados com a nova vida urbana $e$ industrial. Mas, na França, a crise de ansiedade nacional era agravada pela constante 'ameaça alemã'. A comparação com o país vizinho era como um permanente fantasma a ameaçar a soberania francesa. A quantidade e a qualidade 
da população é que poderiam sustentar uma reação frente ao poderio germânico. O comportamento sexual desregulado era então percebido não só como um perigo moral mas também como um perigo biológico que colocaria em risco a própria organização social. A esse comportamento se contrapõe a noção de uma 'maternidade patriótica'. A tensão com a Alemanha e a baixa fecundidade teriam encorajado a retórica populacionista.

A partir de 1875 o número de nascimentos decresce e abre-se um violento debate político entre neomalthusianos e natalistas. Para os natalistas, era preciso combater o individualismo excessivo - que ameaçava a pátria - por meio da valorização da família e da maternidade. Para os neomalthusianos, a superpopulação seria a origem da miséria e da guerra e precisaria ser combatida pelas práticas de restrição da natalidade. Alguns neomalthusianos se associaram ao eugenismo propondo também a 'procriação consciente' dos indivíduos considerados saudáveis e a esterilização dos 'indesejáveis'. O fato é que a queda da natalidade começa a incomodar as classes dominantes e os poderes públicos. Criam-se ligas populacionistas como a Alliance Nationale pour l'Accroissement de la Population Française, fundada pelo dr. Jacques Bertillon em 1896. Instaura-se um clima de medo da ruína nacional a partir da natalidade, e o aborto e a contracepção são identificados como os grandes vilões. A queda da natalidade torna-se um flagelo social. Acredita-se que este fenômeno pode ser responsável pelo declínio da raça, além de colocar em jogo a soberania nacional e o capitalismo industrial na medida em que impediria o crescimento da mão-de-obra e do mercado consumidor (Thébaud, 1986, 1991; Ronsin, 1980).

Na década de 1920, leis intensificariam a repressão ao aborto e à propaganda neomalthusiana, especialmente com a acusação de pornografia e anti-patriotismo. ${ }^{14} \mathrm{O}$ aborto deixa de ser julgado por um júri popular, considerado excessivamente indulgente com os acusados. Os recursos contraceptivos desaparecem das farmácias e os propagandistas das idéias neomalthusianas são severamente perseguidos e condenados. Apesar da repressão, a limitação dos nascimentos torna-se ainda mais forte na década seguinte devido às novas descobertas de Ogino e Knaus sobre o ciclo de fertilidade da mulher. A partir de 1935 os nascimentos tornam-se menos numerosos que as mortes, ameaçando a reposição das gerações (Thébaud, 1986, 1991; Ronsin, 1980). ${ }^{15}$

Francine Muel-Dreyfus (1996), estudando o mito do 'eterno feminino' no regime de Vichy, retoma a discussão sobre como a queda da 
natalidade, ao lado da prostituição e do alcoolismo, foi identificada no começo da década de 1940 como um sintoma do "decaimento nacional". Esta conjunção de problemas teria sido a grande responsável pelas derrotas da França nas guerras de 1870 e 1940 . No regime de Vichy, a queda da natalidade se tornaria uma questão política ainda mais forte. A política familista e natalista converteu-se no remédio que permitiu transformar o clima moral da França, marcado pela união livre, abandono da família, divórcio, egoísmo conjugal, aborto, leviandade sexual e deboche. A família é a célula principal da sociedade. A nação não é um agrupamento de indivíduos, mas de famílias. Era preciso então tomar medidas que a reforçassem, como o combate ao aborto, ao divórcio e ao trabalho feminino, além de dar incentivos às familias grandes e privilégios aos chefes de família. As organizações e movimentos feministas que visavam a defender os direitos das mulheres eram severamente atacados apenas porque estavam tentando destruir os caracteres e as virtudes femininas necessárias à conservação da raça.

O discurso sobre 'as mulheres no lar' e natalidade estava sempre vinculado à raça, ameaçada pela queda da natalidade e pela imigração, especialmente dos judeus na década de 1940. Como os imigrantes indesejados, o feminismo também era percebido como algo que vem de fora, uma criação estrangeira nefasta segundo os interesses franceses. Em contraste, a verdadeira mulher francesa representaria a tradição e a conservação da raça e dos costumes do país. Segundo a autora:

$\mathrm{O}$ apelo à natalidade e à maternidade francesas se inscreve em uma visão política que repensa a história recente em termos da invasão e da poluição por elementos estrangeiros inassimiláveis pelo corpo social. A construção de uma imagem oficial da feminilidade, centrada na maternidade, está em parte ligada à construção do estrangeiro, naturalizado ou não, como ameaça à saúde nacional. Este é sem dúvida o fundamento mais sombrio da sobre-produção do 'eterno feminino' nesse momento de crise. (Muel-Dreyfus, 1996:115. Tradução minha)

A autora descreve como se reforçava nesse momento a imagem da maternidade como destino feminino, especialmente a partir dos discursos médicos, com destaque para ginecologistas, obstetras e puericultores, que combinavam eugenia e política natalista.

Esse laço orgânico entre medicina das mulheres, eugenia e política natalista, que jamais existiu nos países anglo-saxões onde a eugenia reivindicava neomalthusianismo e birth control, confere aos discursos dos homens 
de ciência franceses, médicos e demógrafos, sobre a 'natureza' feminina, uma carga de violência simbólica inigualável. (Muel-Dreyfus, 1996:86. Grifos da autora. Tradução minha)

Uma idéia sempre presente nesse discurso era que a reprodução não pertencia à esfera da vida privada, mas era de interesse nacional. Com base neste interesse era que se devia limitar a educação das meninas, proteger a instituição do casamento e impedir o divórcio. As gerações futuras seriam gratas por este empreendimento médico-estatal. Outra concepção recorrente era a de um retorno à natureza. A civilização era identificada como responsável por uma série de males, como a propagação do controle de natalidade e as tentativas de emancipação feminina. Era preciso então voltar a um mundo mais próximo da natureza, e a mulher aparecia com destaque neste projeto. Afinal, também se afirmava que ela sempre esteve, quando não desvirtuada pela civilização, mais próxima do mundo natural. E era 'da natureza feminina' ser mãe - o que garantia o patrimônio hereditário da pátria - e permanecer no mundo doméstico, o que reafirmava as relações sociais já estabelecidas.

A partir de sua análise, Muel-Dreyfus (1996) sugere como o mito do eterno feminino foi extremamente poderoso nas tentativas de reorganização de uma nação em crise. As justificativas éticas, sociais e políticas que sustentaram as reformas empreendidas pelo Estado francês a partir de 1940, incluindo trabalho feminino, escolarização, política familiar e sanitária, foram ancoradas no mito do eterno feminino, ou seja, na idéia de que existe uma natureza ou essência feminina eterna, impermeável à história e que pode funcionar como garantia para a conservação da sociedade. O ponto central do argumento da autora é que a percepção sobre o masculino e o feminino estruturam o imaginário e a organização de toda a vida social. Em outros termos, propõe que a ordem dos corpos é uma dimensão fundamental da ordem política. E, neste sentido, o retorno à base biológica das diferenças consideradas naturais entre os sexos e a conseqüente definição de destinos masculinos e femininos irredutíveis servem à elaboração de ideologias políticas, como a da homogeneidade nacional francesa.

\section{A Mulher e a Nação Brasileira}

Revendo esta descrição, não se pode deixar de pensar no caso do Brasil. Também aqui as definições sobre a natureza feminina e a reprodução precisam ser percebidas a partir de sua inserção nos processos sociais e 
políticos em cena. Procurarei mostrar como a constante valorização da maternidade e da infância nas primeiras décadas do século XX estava relacionada a um contexto que articulava uma série de fatores, entre os quais se podem destacar a ascensão da ideologia nacionalista, a presença das idéias eugênicas - no caso do Brasil redefinidas a partir dos impasses internos colocados pela miscigenação -, a propagação dos recursos de controle da natalidade, os movimentos de emancipação feminina e a entrada da mulher no mercado de trabalho, além de aspectos relativos a uma redefinição do papel da medicina na sociedade, especialmente da medicina da mulher e da criança.

Também no Brasil as questões da raça e do futuro da nação foram as bases sobre as quais se tentou elaborar um discurso e uma prática que envolviam a definição da mulher como presa ao único destino 'natural' da maternidade. A diferença é que aqui os inimigos eram outros, ou melhor dizendo, o grande inimigo era a degeneração racial relacionada à mistura das raças que constituíam o país, além, é claro, do perigo representado pelas doenças que pululavam da cidade ao sertão, e da imagem de que um extenso território ainda estava para ser povoado.

A questão racial era debatida na época a partir de uma série de aspectos, como a degeneração da raça devido à proliferação da sífilis, ao alcoolismo ou a outros 'flagelos sociais'. Porém, um dos focos mais tematizados pelos intelectuais brasileiros foi o da mistura racial, como descreveu Mariza Corrêa (1998). ${ }^{16}$ A autora, que mostra como medicina e ciência social estavam conectadas nos expoentes da chamada Escola Nina Rodrigues, enfatiza que, desde meados do século XIX, a questão da raça, principalmente sob o prisma da inclusão ou exclusão das massas na vida política do país e na constituição da nação, era uma preocupação constante. Com Silvio Romero e Nina Rodrigues desenvolveu-se um olhar científico sobre o povo brasileiro, inspirado no determinismo biológico, tão em voga na ciência da época. Através da raça poder-se-ia chegar a uma definição da nação e propor as melhores formas de ordenamento social. As análises mostravam que a igualdade formalmente anunciada com a abolição e a proclamação da República não tinha respaldo em dados científicos, que se esmeravam em descrever as diferenças. A partir de Nina Rodrigues, o que se propôs foram formas de regulação da população baseadas na tutela daqueles considerados inferiores e menos responsáveis por seus atos. ${ }^{17}$

Em contraste com o que Muel-Dreyfus (1996) define como o medo do estrangeiro que se cristalizaria na França da década de 1940, aqui a 
ameaça seria de uma "invasão interior", como diz Corrêa (1998) a propósito de Nina Rodrigues. O negro e a miscigenação representavam um perigo potencial, tanto pelas características biológicas que propagariam quanto por uma espécie de contaminação cultural que representariam para outras raças. Os mestiços, assim como outras categorias intermediárias ou ambíguas, como velhos, adolescentes e homossexuais, eram especialmente estudados. Sobre eles recaía de maneira condensada a apreensão relativa à necessidade de estabelecer as fronteiras entre o civilizado e o bárbaro, já que, na medida em que eram 'misturados', poderiam esconder as suas perigosas diferenças. A definição clara destas diferenças era fundamental para a implantação da ordem social (Corrêa, 1998).

Mais tarde, com Leonídio Ribeiro e já em um outro contexto social e político, a atenção se voltaria para a infância, motivada pelo medo da propagação de uma predisposição criminosa. ${ }^{18}$ Corrêa mostra como Leonídio Ribeiro, tratando da infância delinqüente, é capaz de associar em uma única sentença a afirmação da predisposição ao crime, o papel da mulher na sua prevenção e a obra realizada pelo governo de Mussolini de assistência à criança e condenação do aborto. A autora também aponta como as mulheres se associaram aos médicos e a outras autoridades preocupadas em defender a maternidade e a infância. Como Muel-Dreyfus (1996) faria mais tarde para o caso francês, Corrêa sugere que a participação das mulheres - e eu acrescentaria também a elaboração ou reforço de um certo ideal de feminilidade - foi importante na constituição do Estado Novo. ${ }^{19}$ Além disso, lembra que, nesse momento, se processava uma forte tentativa de expulsão das mulheres e crianças do mercado de trabalho.

Margareth Rago (1997), entre outros autores, tem mostrado como nas primeiras décadas do século XX se desenvolve uma grande preocupação com as mulheres trabalhadoras, especialmente do ponto de vista da ameaça que podiam representar à moral social que se tentava estabelecer. O trabalho da mulher fora de casa é descrito por personagens de diferentes segmentos como um perigo para a família e mesmo para a raça. Segundo a autora:

No discurso de diversos setores sociais, destaca-se a ameaça à honra feminina representada pelo mundo do trabalho. Nas denúncias dos operários militantes, dos médicos higienistas, dos juristas, dos jornalistas, das feministas, a fábrica é descrita como 'antro da perdição', 'bordel' ou 'lupanar', enquanto a trabalhadora é vista como uma figura totalmente passiva e indefesa. (Rago, 1997:585) 
Rago ainda acrescenta que esta visão do trabalho feminino está associada a uma vontade de direcionar a mulher para a esfera da vida privada.

A análise que faz Adriano L. Duarte (1999) sobre concepções de família e conjugalidade durante o Estado Novo é reveladora. O autor salienta como nessa época valorizava-se a idéia de uma homogeneidade política e social que refletiria a coesão, a unidade e a ordem necessárias à pátria. Este apelo implicava sobretudo a definição de um modelo de família consonante com os objetivos do Estado e que tentava expurgar o que ameaçaria a ordem pretendida, como a indisciplina, a barbárie, a instabilidade, o atraso, a imoralidade, a sensualidade e a indolência. A população suspeita de incorrer nestes 'delitos' merecia uma ação tanto repressiva quanto profilática e terapêutica.

Tentando modelar o novo cidadão, o Estado Novo visou prioritariamente à família, procurando intervir nas condutas, modos de relacionamentos, relações sexuais, habitação etc. O modelo de família previsto, adequado à construção de uma moralidade pública, era aquele pretendido pelas elites, bem diferente das famílias reais das classes populares. Tratava-se da família nuclear, sem inúmeros agregados, que tinha uma habitação própria e não morava nos cortiços sem privacidade, calcada no casamento indissolúvel, no homem como provedor e na mulher 'do lar', mãe e educadora. O trabalho e a presença feminina nas ruas eram bastante condenados. A mulher modelo do Estado Novo tinha como atributos a timidez, a ingenuidade, a prudência, a fragilidade e a abnegação, opondose às transgressoras, devassas, libertinas, separadas, que circulavam livremente nas ruas. A estas últimas correspondiam as "famílias desestruturadas pelos casamentos desfeitos, pelas mancebias e amasiamentos, pelas mulheres que trabalhavam fora, pela insuficiência dos rendimentos, pelos maridos violentos, alcoólatras, as crianças delinqüentes, os biscateiros, mendigos, prostitutas e vadios" (Duarte, 1999:205).

Estas informações já nos dão uma idéia de como a questão da reprodução e do papel da mulher na sociedade eram atravessadas pelas apreensões quanto ao futuro do país. E isto considerando as 'dificuldades' percebidas tanto em relação as nossas 'disponibilidades raciais' quanto a um certo número de 'doenças' bastante freqüentes. É necessário dizer que este tipo de reflexão e de apreensão era resultado da configuração de um vasto e poderoso conjunto de idéias centradas no problema da 'população', que vinha sendo gestado na elite intelectual brasileira desde o século XIX. 


\section{A Ciência e o Interesse pela População}

Nas últimas décadas do século XIX pode-se identificar a disseminação de uma nova perspectiva social e política que teve sérias repercussões nas análises e projetos sobre a realidade social brasileira. Intelectuais e, sobretudo, médicos, inspirados nas teorias sociais, desenvolvimentos científicos e movimentos políticos europeus, pregavam uma nova era para o país.

A partir da década de 1870 assistia-se a um movimento de diversificação das elites intelectuais nacionais retratada na multiplicação das instituições científicas, como os museus, as faculdades de direito e medicina e os institutos históricos e de pesquisa. Tanto a formação quanto a aspiração profissional variavam. E mais do que o pertencimento a uma classe social ou grupo político, o que caracterizava estes novos intelectuais era a tentativa de respaldar as suas posições na ciência, partindo das instituições as quais integravam. Além disso, era toda a sociedade brasileira que passava por um período de transformações, a destacar o crescimento das cidades e de sua importância e uma nova configuração das elites político-financeiras que se dividiam entre os antigos canavieiros nordestinos e as elites cafeeiras do Rio de Janeiro e São Paulo. O debate sobre o sistema escravocrata, o fim da Guerra do Paraguai e a campanha republicana ilustravam o tom de turbulência do momento. Novas idéias quanto à política, à religião, ao trabalho eram postas em cena. E passava-se a explicar cientificamente o atraso nacional com base, especialmente, na composição racial. A miscigenação preocupava aqueles que pensavam o futuro da nação (Schwarcz, 1993).

As novas correntes teóricas que se desenvolviam na Europa faziam eco no Brasil. O evolucionismo social, o positivismo, o naturalismo e o darwinismo social ganhavam adeptos. A profissão de cientista era valorizada quase como um sacerdócio. Na Europa, as ciências sociais tentavam construir um rumo próprio. As ciências naturais se especializavam e eram ainda mais valorizadas. A biologia se tornava o grande modelo. Aqui, tentava-se uma aproximação com o mundo europeu através da construção da imagem de uma nação científica e moderna. A ciência virava moda e era cultuada nos jornais e nos romances naturalistas. Nas cidades, a onda dos programas de higienização e saneamento contribuía para este movimento. Embora houvesse, por um lado, a valorização da racionalidade científica que justificava inúmeras medidas de intervenção; por outro, percebia-se também o distanciamento do povo em relação a estes programas, como a 
Revolta da Vacina iria ilustrar em 1904. O importante era que os homens de ciência tentavam mostrar como as suas contribuições, pensando modelos e lógicas, eram fundamentais e prioritárias para as soluções dos problemas do país (Schwarcz, 1993).

A pobreza e doença eram percebidas como as fontes principais desses problemas. Nos diagnósticos e propostas dos reformadores higienistas, as classes pobres eram vistas como perigosas não só porque representavam obstáculos à organização do trabalho e manutenção da ordem pública, mas também porque poderiam contagiar outras classes. Essa população, assim como as zonas da cidade que habitavam, precisavam passar por um processo de higienização e civilização. No imaginário de políticos e higienistas da época, tratava-se de uma libertação do atraso que representava o período colonial e da inauguração do caminho em direção à civilização nos moldes europeus. A higiene convertia-se em uma ideologia do progresso calcada nos pressupostos científicos vigentes. Segundo Sidney Chalhoub (1996:35), esta ideologia pode ser entendida:

como um conjunto de princípios que, estando destinados a conduzir o país ao 'verdadeiro', à 'civilização', implicam a despolitização da realidade histórica, a legitimação apriorística das decisões quanto às políticas públicas a serem aplicadas no meio urbano. Esses princípios gerais se traduzem em técnicas específicas, e somente a submissão da política à técnica poderia colocar o Brasil no 'caminho da civilização'. Em suma, tornava-se possível imaginar que haveria uma forma 'científica' - isto é, 'neutra', supostamente acima dos interesses particulares e dos conflitos sociais em geral - de gestão dos problemas da cidade e das diferenças sociais nela existentes.

Os primeiros governos republicanos investiam no projeto de fazer do Brasil um Estado-Nação moderno, seguindo os modelos europeus. Um grande esforço era feito por estadistas, intelectuais, homens públicos e imprensa no sentido tanto da ampliação da atuação do Estado sobre a sociedade e o território quanto de uma maior articulação das forças sociais. Esse esforço podia ser visto na presença mais intensa do poder público central em todo o país, na ampliação da burocracia estatal e na multiplicação dos campos de ação do governo. O Estado passava a se preocupar com "a manipulação estabilizadora da opinião pública; o alargamento progressivo do controle centralizador sobre a massa territorial; o desenvolvimento de uma atuação beneficente e tutelar sobre os grupos urbanos, capaz de amenizar conflitos sociais e a ampliação e reforço das forças marítimas e terrestres" (Sevcenko, 1983:47-48). ${ }^{20}$ 
Sobre esta configuração de idéias era que engenheiros e médicos se apoiavam para legitimar seus projetos de saneamento. Para Madel Luz (1982), entre as décadas de 1870 e 1920, as políticas higienistas de inspiração francesa, formuladas na parceria entre medicina e Estado, caminhavam no sentido de garantir um maior controle da população e esquadrinhamento do espaço urbano. Nesse período, o movimento sanitarista desdobrava-se em uma série de facetas que recobriam desde o higienismo do tipo eugênico, a engenharia sanitária, a realização de campanhas, até a higiene moral e a educação. Este amplo empreendimento social e político estaria relacionado a questões mais amplas, como o advento da ordem social capitalista e a formação do Estado:

Pode-se dizer, assim, sem risco de erro profundo, que a história da constituição das instituições de saúde pública é a história da tentativa de uma dupla resposta da medicina: de um lado, à ordem social que se instaura no Brasil com a estrutura capitalista de produç̧ão, às suas contradições no plano da saúde; de outro, do poder que se constitui nessa estrutura com o Estado Nacional. (Luz, 1982:21)

A relação entre políticas sanitárias e maior controle da população por parte do Estado aparece em outros exemplos. Luiz Antonio de Castro Santos (1980, 1985, 1993), estudando a ampla e bem-sucedida Reforma Sanitária ocorrida no estado de São Paulo no início do século XX, mostra como a implementação de políticas de saúde e o reforço do poder estatal caminhavam juntos nesse momento. A construção de um aparelho burocrático, a organização de um corpo de leis de saúde pública, a criação e implementação de uma política sanitária além de um desenvolvimento científico particular foram expressões não de demandas populares, mas da necessidade de modernização do país proclamada pelos centros de poder nacional e regional.

Tratou-se de uma modernização vinda do alto, baseada na centralização administrativa das instituições e ações de saúde e saneamento, que tinha como função contribuir para mudanças estruturais que garantiriam o progresso urbano, comercial e industrial, rural, agrícola. Este projeto de saúde pública centralizada desenvolvido em São Paulo, na medida em que serviu de modelo para as políticas adotadas na era Vargas, contribuiu de maneira ímpar para a construção nacional e a formação de uma idéia de nacionalidade. De acordo com Santos (1993:387): 
Os reformadores paulistas juntaram-se ao movimento nacional pela 'salvação dos sertões', buscando integrar as populações do interior, castigadas por doenças, aos modos de vida urbana e aos valores 'civilizados' da nação brasileira. O que estava em jogo era a formação de indivíduos com consciência cívica, comprometidos com a construção de uma nova nação.

Desde o Império, especialmente a partir do combate às epidemias, as preocupações e práticas em relação à saúde caminhavam lentamente para a centralização administrativa até se tornarem um problema eminentemente público. Contudo, embora a reforma dos serviços sanitários já estivesse em pauta no início da República, foi a campanha pelo saneamento rural que expandiu para um círculo bem mais amplo, não mais exclusivamente médico-científico, o projeto de saneamento. Nesse processo, a questão da saúde passava a incorporar também um conteúdo eminentemente político. Para Gilberto Hochman (1998:16):

Uma política nacional de saúde pública no Brasil foi possível e viável a partir do encontro da consciência das elites com seus interesses, e suas bases foram estabelecidas a partir de uma negociação entre os estados e o poder central, tendo o federalismo como moldura políticoinstitucional. Esse encontro foi promovido pelo movimento sanitarista brasileiro que buscou redefinir, entre 1910 e 1920, as fronteiras entre os sertões e o litoral, entre o interior e as cidades, entre o Brasil rural e o urbano em função do que consideravam o principal problema nacional: a saúde pública. (Grifo do autor)

Esse movimento teve conseqüências nas discussões sobre a formação da nação brasileira. Diagnosticava-se que esta nação ainda não existia e tinha de ser construída. A autonomia dos estados e a ausência da presença de um Estado forte, atuante e centralizado contribuíam para o isolamento e atraso das regiões mais distantes. Este atraso ficava evidente sobretudo na área da saúde. Percebia-se o Brasil como um enorme país doente. Achava-se que o povo brasileiro não tinha nenhum sentimento de nacionalidade. Para alguns intelectuais, a herança racial não permitia que se tivesse uma expectativa de grandes melhoras. Para outros, como os ideólogos da campanha do saneamento, a preocupação com o determinismo racial dava lugar à idéia da doença e do isolamento do povo brasileiro como problemas fundamentais, mas que poderiam ser resolvidos.

Na verdade, a doença era a única coisa que dava uma unidade ao país e, ao mesmo tempo, que impedia os progressos nacionais. Do ponto 
de vista daqueles que encampavam o movimento sanitarista, era preciso que as elites se convencessem da necessidade do término dessa situação e investissem em uma política que centralizasse as ações na área da saúde. Esta foi a proposta básica do movimento liderado por médicos-higienistas, que durante a década de 1910 investiu no saneamento do país, visando a recuperar o povo que estava doente e isolado e transformá-lo em cidadãos de uma nação civilizada (Lima \& Hochman, 1996).

A nova concepção de saúde e doença e as reformas sanitárias empreendidas seriam parte de um conjunto de adaptações aos novos interesses comerciais e financeiros. É nesse contexto que a idéia de saúde pública se impõe, não apenas como forma de controle das doenças, mas fazendo parte do processo de constituição das relações políticas. A formação de uma burocracia sanitária e as novas concepções na área da saúde respondiam às demandas de representações e formas de controle para diferentes classes sociais. A partir da década de 1920 a necessidade premente de reorganizar o mercado de trabalho dava origem a novas modificações na relação entre Estado e saúde pública.

Tomando o exemplo do estado de São Paulo, Massako Iyda (1994) mostra que até 1925, ano de importante reforma do Serviço Sanitário, predominava a criação de hospitais de isolamento e de doentes mentais, além de serviços laboratoriais que eram as bases para o controle de doenças específicas. A partir de então, o Serviço Sanitário ampliava suas atividades, com destaque para a proteção à infância e profilaxia em geral. A saúde pública, já incorporada definitivamente ao Estado, tinha como atribuições o controle das doenças transmissíveis, a higiene do trabalho, a alimentação, a escola e, posteriormente, a partir da década de 1930, a tuberculose, a febre amarela, a assistência dentária, a sífilis e as doenças venéreas. Nessa trajetória, a educação fazia par com a medicina, passando a ocupar um papel de destaque na empreitada de constituição do novo modelo de trabalhador e cidadão.

Este rápido percurso por alguns movimentos que marcaram o processo de ocupação de um amplo espaço social e político pela medicina desde o final do século XIX até as primeiras décadas do século XX serve para se ter em mente o quadro no qual a reflexão e as propostas de intervenção da medicina na reprodução aconteceram. Gostaria de chamar a atenção para o fato de que a medicina era mais reconhecida e prestigiada à medida que tomava para si o problema da constituição da nação. É através da preocupação com a civilização, a higiene, o saneamento em prol da 
construção de uma nação forte e saudável que os médicos passavam a ocupar cargos públicos importantes, fundar novas instituições e aumentar seu poder de intervenção social. Ao mesmo tempo, os diagnósticos oferecidos por eles sobre a natureza dos problemas brasileiros, especialmente no que concerne à doença e à raça, e suas interpretações sobre as possibilidades de regeneração passavam a difundir-se e a ter respaldo na sociedade. $O$ pensamento médico científico configurava-se como um dos principais alicerces para o desenvolvimento do debate em torno da nação nesse período. $\mathrm{E}$ as contribuições médicas específicas sobre a reprodução e a mulher estavam plenamente associadas a esse empreendimento. Além disso, eram algumas pressuposições e mesmo algumas categorias oriundas da medicina que mais diretamente respaldavam a atuação do nosso sistema jurídico-policial no tratamento dos casos referentes a aborto e infanticídio.

\section{Notas}

1 Ver as seguintes teses: Guimarães (1872), Silva (1873), Gondim (1911), Campos (1912), Carvalho (1922), Cesar (1924), Andrade (1928).

2 As tentativas de resolução do problema também vão se aprimorando. Uma técnica que já é utilizada há algum tempo mas que passa a ser muito citada é a da fecundação artificial. Em uma resenha publicada no Brazil Medico, em 1912, era descrita da seguinte forma: “A técnica da fecundação artificial é simples. Estando tudo preparado, faz-se com que o coito se realize com um condom (camisa de Vênus), onde o esperma se ajunta, recolhe-se-o depois em uma cápsula esterilizada, e com uma seringa de Braun injeta-se um pouco dele no útero" (Brazil Medico, 1912:314).

3 Em 1910, o Brazil Medico publicava a tradução de um artigo de Mme. Laborie que defendia que as causas da esterilidade deveriam também ser pesquisadas no homem, pelo exame dos órgãos genitais e do esperma. No mesmo texto, são fornecidas recomendações para a profilaxia da esterilidade. Destaca-se a noção de que o momento mais favorável para a coabitação fecunda é nos dois ou três dias que precedem as regras ou nos três que lhes seguem. Também se deve levar em consideração "que a moça que vai casar dever ter um desenvolvimento normal e completo; que o marido deve ter quatro ou cinco anos mais que a mulher, e possuir potência sexual normal; que os cônjuges não sejam parentes; que as viagens da 'lua de mel' são prejudiciais pela fadiga que produzem, pela freqüência das relações sexuais, com falta de conforto e às vezes de higiene" (Brazil Medico, 1919:279-280).

4 É importante lembrar que o termo raça, nesse debate, diz respeito menos ao que qualificaria uma suposta distinção entre o que seria uma 'raça branca' ou uma 'raça negra', referindo-se na maioria das vezes à idéia de 'povo' ou mesmo 'espécie'. Utili- 
za-se, por exemplo, raça como sinônimo de povo ou espécie, ao se falar do 'aperfeiçoamento da raça/povo brasileiro' ou do 'futuro da raça/espécie humana'. O uso do termo raça neste trabalho, na medida em que implica a reprodução do debate em torno de povo ou população, reproduz essa acepção.

5 McLaren (1990) mostra como há um amplo debate, especialmente entre os demógrafos, sobre essa transição demográfica e, entre outros especialistas, sobre as causas de um maior controle da natalidade. Ver também Guillaume (1996).

6 Shorter (1982) também descreve os métodos tradicionais, as drogas e os instrumentos utilizados no período.

7 Smith-Rosenberg (1985) destaca ainda que, nos Estados Unidos, as campanhas empreendidas pelos médicos contra o aborto tiveram uma repercussão extensa. Também afirma que os médicos envolvidos nas campanhas estavam especialmente preocupados com a moralização da profissão, especialmente da ginecologia.

8 Fine (1986) descreve como os procedimentos populares usados na França do século XIX são parecidos com a terapêutica médica da amenorréia.

9 A designação de 'neomalthusianos' era aplicada para identificar aqueles que propunham a restrição voluntária do número de filhos através do uso de métodos de controle da natalidade. Sobre a teoria de Malthus e sua apropriação posterior pelos neomalthusianos, ver Ronsin (1980).

D Esta característica também é identificada no contexto atual para mulheres de camadas populares. Ver Leal (1995).

1 Ver também o importante trabalho de Brodie (1994).

口 Bardet e Dupâquier (1986) apresentam detalhadamente essa discussão.

13 A ginecologia, diferentemente da obstetrícia - que é bem mais antiga -, surge de forma mais institucionalizada apenas nas últimas décadas do século XIX. Moscucci (1996) analisa em profundidade este processo. Para o caso brasileiro, ver Rohden (2001a; 2002a).

4 Também na Alemanha (1900) e na Inglaterra (1857), leis previam a condenação da propaganda contraceptiva (McLaren 1990).

5 Dupâquier (1986), que organizou as estatísticas sobre aborto na França até 1914, concluiu que esta prática aumentou nos primeiros anos do século XX. Até 1920 a publicidade em favor do aborto era praticamente livre, com pouca repressão.

16 Ver os trabalhos de Seyferth $(1989,1996,1997)$ que tratam também da imigração. Sobre a questão racial, mais especificamente do ponto de vista dos eugenistas, ver Stepan (1990).

1 Um dos resultados atrelados a essa concepção foi a política de identificação elaborada cientificamente e utilizada nos meios jurídicos e policiais (Cunha, 1998).

18 Arthur Ramos também se preocuparia muito com a criança e com a figura materna, mas seguindo outra direção (Corrêa, 1998).

19 Sobre o movimento feminista na década de 1930 e suas aproximações como o Estado Novo, ver Callado (1994).

w Um foco importante de controle e tutelarização foram as tentativas de institucionalização da loucura. Para um panorama desse movimento, ver Engel (2001). 